\title{
From Learning English in a Colony to Working as a Woman TESOL Professional of Color: A Personal Odyssey
}

Angel M. Y. Lin, Associate Professor, Department of English, City University of Hong Kong, Tat Chee Ave, Kowloon, Hong Kong; fax: (852) 2788-8894; phone: (852)

2788-8122; e-mail: enangel@cityu.edu.hk

Lin, A. M. Y. (2006). From learning English in a colony to working as a female TESOL professional of color: A personal odyssey. In A. Curtis, \& M. Romney (Eds.), Color, race, and English language teaching: Shades of meaning (pp. 65-80). Mahwah, New Jersey: Lawrence Erlbaum.

\section{A. Learning English in a British colony}

I do not belong to the small number of people in Hong Kong who have been born into families and communities which provide them with ample English linguistic and cultural capital (Bourdieu, 1982/1991; Delpit, 1988) to succeed in school in a British colony, where English is the key to academic success and socioeconomic advancement. My parents do not speak any English. People we know all speak Cantonese which is our daily language. I grew up in a home and community where few had the linguistic resources to use English at all, and even if anyone had, she/he would find it extremely socially inappropriate (e.g., sounding pompous, putting on airs) to speak English.

My chances for learning and using English hinged entirely on the school. However, I lived in a poor government-subsidized apartment-building complex (called "public housing estate") in the rural area (the New Territories) in Hong Kong, where schools were mostly newly put up in the 1960s and they neither had adequate English resources (e.g., staff well-versed in spoken English) nor a well-established English-speaking and English-teaching-and-learning tradition or school culture.

My parents were poor manual workers. They put all their hopes and expectations in their children: illiterate in English as they were, they did not fail to be keenly aware of the fact that their children's future depended on doing well in school, and doing well in school depends on mastering the English language in the Hong Kong schooling system.

They have passed on the work ethic to their children. We were urged day and night to "study hard" and especially to study English hard though they themselves did not have the slightest idea as to how one could learn English well! I remember that when I was in Grade 3, I was very frustrated by my English "story book" which was full of difficult English words that I did not understand. My teacher then typically read the story once and I could not remember how to pronounce those words afterwards. The whole page was opaque and frustrating to me! I was very frightened then because small as I was, I did not fail to realize that I was not going to do well in English. 
Upon leaving the primary school, I got good results in the secondary school entrance examination and got admitted to an English medium secondary school. However, unlike when I was in Primary 3, I didn't despair and I would spend hours and hours looking up all the new words in the dictionary and write down their pronunciations (in phonetic symbols), meanings and examples in a vocabulary notebook and read them whenever I had time. My history textbook had become a rich source of vocabulary learning and soon I could catch up with the history lessons and assignments.

\section{A Community of English Letter Writers}

In my circle of girl-friends, having pen-pals had become a topic and practice of common interest and we would talk about our pen-pals and shared our excitement about trading letters, postcards, photos, and small gifts with our pen-pals; we'd also show one another pictures of our pen-pals. We'd share things like different kinds of beautiful letter pads and envelopes, and about what to write to our pen-pals, etc. Although there wasn't a pen-pal club, we had, in a way, formed our own informal pen-pal-interest group (without having such a name and formal structure, of course). It was a spontaneous "community of practice" (Lave and Wenger, 1991) that had emerged from our own activities and interests. Through organizaions such as Big Blue Marble or International Youth Service I got penfriends from England, Austria, Canada and the United States and we communicated regularly in English by air mail letters. Sending letters to our overseas penfriends and waiting eagerly for their replies had become our everyday hobbies.

\section{Expressing Alternative and Expanded Selves in English}

I also started to write my own private diary in English every day about that time. I started this habit when a pen-pal sent me a diary book as my birthday present and suggested writing diary as a worthwhile activity to me. I chose to write my diary in English because someone (a teacher? I don't remember now) had told me that finding a chance to use English daily would improve one's English. I felt that I could write my feelings more freely when I wrote in English--less inhibition and reservation--I seemed to have found a tool that gave me more freedom to express my innermost fears, worries, anger, conflicts or excitement, hopes, expectations, likes and dislikes, or my alternative selves, without constraint or inhibition--as if this foreign language had opened up a new, personal space (a "third space", so to speak), for me to more freely express all those difficult emotions and experiences (typical?) of an adolescent growing up, without feeling the sanctions of the adult world. I guess I was creating an expanded self in English, and English seemed to provide me with the additional resources I need to explore myself in a somewhat different manner, in a somewhat different value system, one that appeared to be less prohibiting than my native language in some areas, for instance, in the area of explicitly articulating one's emotions like anger.

English, it seems, had opened up a totally new space for me to express and entrust my secrets and innermost feelings--I felt safe to confide in Gretchen, my US pen-pal, and to my diary. I also felt that English had provided me with a tool to broaden myself, to reach out to new friends in new lands, to invent and recreate for myself a somewhat different self 
from the one my parents know. It gave me excitement when new and lasting friendships across cultural and geographical boundaries were formed, and it gave me satisfying feelings like those that an adventurer would have exploring into a new land and new culture. Of course, all the while, I also felt that I had developed a good, healthy hobby which would help to improve my English proficiency and my performance in school, which was equally important to me. This experience of mine has made me aware of the importance of creating opportunities for students to use the language that they are learning to expand their sociocultural experiences, to explore cross-cultural issues, to negotiate hybridized and expanded selves and identities. If they can appropriate English and penetrate it with their own meanings, intentions and voices and use it for their own purposes then English will no longer be a 'foreign' or 'alien' language and it will become a language of their own. This has motivated my later research and work on how to help students to 'hybridize' English and appropriate it to express their own meanings (see Lin \& Luk, 2005; Lin, Wang, Akamatsu \& Riazi, 2002).

\section{Anti-Crisis: Being made to feel ashamed of my accent}

English in my secondary school days was something I felt I mastered and owned. I felt competent and comfortable in it. It was not until my first year as an undergraduate English major in the University of Hong Kong that I was induced to feel ashamed about my own English—or made to feel that I hadn't really mastered it or owned it. Many of my fellow students at the university had mostly studied English literature in their secondary schools, while I had only the slightest idea of what it was! When I opened my mouth in tutorial sessions, I noticed the difference between my Cantonese-accented English and the native-like fluent English that my classmates and the tutor spoke. It was, however, too late for me to be able to pick up the native-like accent then. Besides, there were not many chances for me to learn to interact with people face-to-face in English informally.

My disadvantage and my lack of spoken English resources became more painfully evident when upon graduation I started teaching English in a well-established girls' school. When my most advanced students began mocking my accent in the classroom, I knew that I had to quit and return to the university to acquire more English resources and credentials..

Fortunately, I succeeded in getting a scholarship to live in the Robert Black College at the University of Hong Kong for two years during which I studied for my master's degree in Applied Linguistics. It is a lush residence primarily intended for visiting professors, scholars, researchers and overseas graduate students. However, they also offered a small number of residential scholarships to local Chinese graduate students to enable them to live there (e.g., subsidizing their room and board which would otherwise be too expensive for a local student). For the first time in my life, I lived in a community and a lifeworld where English was informally used, and where I could interact and make friends with English-speaking people in my daily life (vs. in a formal lecture).

My life and career took a turn after my master's degree and my residential years in the Robert Black College. I have acquired both the paper credentials and the actual linguistic 
and cultural resources to get and do the job of an English teacher. I had not (and have not) acquired a native-like English accent, but relatively speaking, my spoken English was more fluent and idiomatic than before the Robert Black College years. I no longer felt that I was an "impostor" (Bourdieu, 1982/1991), or an "incompetent" teacher, an object of mockery by my middle-class students and colleagues. I seemed to have somehow managed to enter the elite group of English-conversant Chinese in Hong Kong.

I was about to settle down with the job of an English language instructor at the University of Hong Kong and forget about the past. After all, I had worked hard and managed to move up the socioeconomic ladder and fulfill the expectations of both my parents and myself. I had a better job now compared with the jobs my parents had, and they need not worry about my future any more.

However, when I think of all that had happened I realize that my own chances for socioeconomic advancement seem to have hinged largely on a certain exceptional re-patterning of social and institutional arrangements. Although individual hard work is necessary, individual hard work and sacrifice alone do not count much. For all the hard work in the world, I would not have been able to develop my interest in and ability to learn English, had there not been some well-trained and English-conversant teachers who were willing to teach in a rural school (and this was an exception rather than the rule), and who provided me with access to some English linguistic capital. For all my hard work, I did not manage to attend one of those well-established, prestigious English-speaking schools in the urban area because of the extremely prohibitive distance constraint imposed by my rural residential location. For all the hard work in the world, I would not have had access to conversational English resources, had there not been an institutional arrangement to provide some local students with scholarships to live in the English-speaking Robert Black College (and again, the number of scholarships was very small). My own personal history has led me to realize that certain social and institutional structures impose strong constraints on a child's opportunities for bettering her/his life quite independent of her/his efforts and industry. For someone coming from a sociocultural and socioeconomic background like mine, the chances for socioeconomic advancement are slim even with lots of individual hard work and enterprise. These social and institutional arrangements constrain the child's opportunities for socioeconomic advancement by denying or limiting her/his access to English linguistic and cultural resources.

It would not be too much of an exaggeration to say that success in learning and mastering English (and thus also other subjects, which were tested in English in most secondary schools) can be next to a "life-and-death" matter for a school child in Hong Kong ${ }^{1}$; her/his academic success, social mobility, social status, higher education and job opportunities, and very often and very immediately, in the student's as well as their important others' (e.g., their parents') minds, the student's own self-worth directly or indirectly depends on it. We

${ }^{1}$. Instances of secondary school students committing suicides before public exams and after public exam result announcements are not uncommon in Hong Kong. Youth suicides are also not uncommon; for instance, in 2001, there were 3.7 cases of youth suicide per 100,000 people in the population of over 6 million people in Hong Kong (http://hk.geocities.com/waimanchester/waimanchester.htm). 
may be justified to call it the "language of self-worth". Notwithstanding its being the mother tongue of only a minority in Hong Kong, English is both the language of power and the language of educational and socioeconomic advancement. It constitutes the dominant symbolic resource in the symbolic market (Bourdieu, 1982/1991) in Hong Kong.

The symbolic market is embodied and enacted in the many key situations (e.g., educational settings, job settings) in which symbolic resources (e.g., certain types of linguistic skills, cultural knowledge, specialized knowledge and skills, etc.) are demanded of social actors if they want to gain access to valuable social, educational and eventually material resources (Bourdieu, 1982/1991). For instance, a Hong Kong student must have adequate English resources, in addition to subject matter knowledge and skills, to enter and succeed in the English-medium professional training programmes of medicine, architecture, legal studies, etc. in order to earn the English-accredited credentials to enter these high-income professions. The symbolic market is therefore not a metaphor, but one with transactions that have material and social consequences for individuals.

I therefore pursued doctoral studies and did a critical study on the sociocultural contexts of English language lessons in Hong Kong schools (Lin, 1996). However, earning a doctoral degree and entering into the TESOL academia became just the beginning of another difficult journey. Looking back on my past seven years of experiences in the university is painful; it's like looking at one's scars and all that one has sacrificed to gain respect and dignity in one's job. I shall turn to this in the next section.

\section{B. Working as a woman TESOL professional of color in Hong Kong}

Ever since the very moment of being hired I have been constituted as "a local classroom person" and designated to do the labor-intensive work of student practicum supervision and school placement coordination.

I learnt later that at the time they hired me, they had two positions. One position was to replace a local (i.e., non-white, Cantonese-speaking) faculty member who was leaving academia to return to a secondary school to become the principal there again. The local colleague had contributed the lion's share of the work setting up the undergraduate programme's internship curriculum. She had been doing both the heavy administrative work of soliciting from schools every year the placement positions for the programmes, as well as developing the internship manual, assessment, portfolio, and journal protocols for the course. The other position was for someone to teach second language acquisition (SLA) and TESOL research methods.

Although I had extensive training in research methodology, including both qualitative, ethnographic methods and sophisticated statistics and measurement theories and techniques (e.g., path analysis and LISREL [linear structural relations], factor analysis, and other types of inferential statistical analyses), my employer seemed to ignore all my research training (which was stated on my CV) and just focused on me as a "local classroom person" because my thesis research was a sociocultural and discourse analytic study of local classrooms. I later learnt from my Caucasian colleague from the United 
States who filled the other position that when he was employed, he was told that they needed a local person for teaching the classroom modules and doing the work of student practicum placement coordination and needed him for teaching the SLA and research methods modules.

So, from the very beginning of my existence as a faculty member there I was both constituted and pigeonholed as a "local classroom person", which has all the consequences of giving my superiors the rationale for assigning me to the labor-intensive, administrative-heavy workload that the senior Caucasian members will choose not to have. Another very useful rationale is found in the argument that they need someone who speaks the local language (and preferably a woman--isn't a woman traditionally most suitable for a public relations job?) to liaise with the schools in soliciting practicum places for our students. Whenever we counter-argued that the local school personnel do speak English, the superiors would argue that it would be better to have a local person who is said to be 'more familiar' with the local schooling system when liaising with school personnel. This argument assumes that the senior faculty members from overseas (all Caucasian native English speakers), first do not need to learn at least some local language of the students and teachers, and second, do not need to get themselves more acquainted with the local educational issues and schooling system. One wonders in what ways they can fully benefit our pre-service and in-service student teachers if they take it for granted that it is okay for them to remain not very familiar with both the local educational issues and the local linguistic and cultural milieu of our student-teachers and their future students. And of course, we argued the way we liked, and they assigned us the jobs the way they liked. .

Another instance also speaks to their pigeonholing me as a classroom person. Two years ago I was Deputy Programme Leader of our undergraduate TESL programme. However, one day I was told by my Chinese male colleague who was Programme Leader that they would like to have my British colleague become the Deputy Programme Leader to boost the public profile of our TESL programme in the local communities. My British colleague did not have a PhD but was a playwright doing some English radio educational programmes part-time, and a Caucasian British and native English speaker. The Programme Leader's exact words were: "It'd be better to have a native-English-speaker as our Deputy Programme Leader--it will increase the prestige of the programme, as local students and parents look up to foreign, native-English speaking experts." I was asked to give up Deputy Programme Leadership to take up the heavy administrative, coordinator work of the practicum module AGAIN (after my many years of doing it previously). I protested on e-mail to my Chinese male colleague, saying that what he proposed would only reproduce the society's denigration of local English staff. He replied that he wouldn't want to enter into such a non-fruitful argument with me, and said all he cared about was the good of the programme.

I held nothing personal against my British colleague or my Chinese male colleague. Both of them had been and are still on friendly terms with me. I fully understand that this is what my Chinese male colleague truly believes in: a British name and a Caucasian face put on our undergraduate programme will boost our public image. However, what I felt agonized about is that all these years of solid training and researching intensively the local 
educational issues had only earned me a "second-class" status in the TESOL profession. I still think that my male Chinese colleague was "well-intentioned" (i.e., "for the good of the programme") but he had let the ideology of native-speakerism speak and exercise through him (Gee, 1996) and he was totally unaware (or refused to be aware?) of the kind of injustice done to me through reproducing this ideology that privileges white people in his actions as he exercised his power unjustly.

Every workplace is liable to internal politics and there are struggles that are related not only to race/ethnic/linguistic background or gender. Thus marginalization can happen to anyone, including white male and female faculty. It is important to note that gender and racial categories should be seen as relational and not categorical, and do not invariably prescribe a particular type of social experiences for members of those categories (and membership can sometimes be negotiated). Thus we should refrain from taking an essentializing approach to our experiences. And yet, my lived experiences of marginalization point to certain systematic ideological and institutional structures underlying them. It is to a theoretical analysis of these structures that I shall turn below.

\section{Gendered and racialized task/labor segregation in TESOL}

My lived experiences point to a common pattern of gendered and racialized task and labor segregation; i.e., women faculty of color are often assigned to labor-intensive administrative and teaching duties (e.g., I was consistently asked to do the heavy administrative work of liaising with schools for students' teaching practicum). Two decades ago feminist standpoint theorists already pointed out the gendered labor segregation in modern academia. For instance, Dorothy Smith $(1974,1987)$ argues that "women's work" relieves men of the need to take care of the everyday, practical chores of the local places where they exist, freeing men to immerse themselves in the world of abstract concepts and theories. Moreover, the more successfully women perform their work, the more invisible does it become to men. This is precisely what was experienced by faculty of color in HK. Without the heavy administrative work of women faculty of color like me to secure places for students' practicum every year, our department's TESOL programme cannot be viable. The largely white male faculty just enjoys the benefits of their labor and they can focus on teaching "theoretical” courses and writing research papers or taking up leadership roles in the department. We therefore need to extend the model of the feminist standpoint theorists to point out that this segregation of labor is very often not only gendered but also racialized. We can draw a parallel between task segregation in modern academia and the well-documented task/labor segregation in $19^{\text {th }}$ century United States:

A pattern of task segregation can also be historically demonstrated. Although the classical example is the sole use of black slaves in growing cotton, task segregation occurred with other racial minorities as well. (Liu, 2000, p. 1351)

Liu (2000) went on to describe the internal colonialism in $19^{\text {th }}$ century United States under which racial minorities such as Chinese and black labors were concentrated in the low-priced, low-wage fields, primarily in agriculture and import-competing industries 
while the majority of white workers were in the high-priced, high-wage fields and in non-competing industries. I argue that such an invisible internal colonial model is also in operation in today's academia, especially in the TESOL discipline, where a pecking order of tasks seems to exist. It is to an analysis of the epistemological and political consequences of this task hierarchy and task segregation that I shall turn in the next section.

\section{The great theory--practice divide in TESOL}

TESOL as an institutionalized discipline is relatively young compared with other "hard" sciences or even social sciences (e.g., psychology). As an academic discipline it has always aspired to "scientific status" by ever improving its theories through research done mainly in the positivist, physicalist tradition, and chiefly in the sub-disciplines of second language acquisition and inter-language studies. As an "applied" discipline, it has borrowed extensively from both the theories and research methodologies of other "pure" disciplines such as Chomskyan linguistics, psychology and cognitive science. While recent years have seen the discipline's top journals becoming more receptive to research done in post-positivist, sociocultural, or critical paradigms, mainstream TESOL theoretical and research canons still follow the parent disciplines which are modern academic disciplines established in the tradition of Enlightenment rationality and philosophy. Modern disciplines born of the Enlightenment tradition subscribe to specific sets of ontological and epistemological assumptions. Under Enlightenment assumptions, the ideal agent of knowledge, the ideal scientist, is a transhistorical, unitary, individual and a disembodied mind, whose scientific endeavours are not supposed to be in any significant ways shaped or constituted by their historical, social, cultural and institutional contexts and locations. The contents of their discoveries, the theories and findings, likewise are eligible to lay claims to the status of transhistorical, universal truths (for a summary of feminist standpoint critiques of Enlightenment epistemology, see Harding, 1996). In practice, mainstream TESOL research largely follows the paradigm of positivism and physicalism. The chief concern under this paradigm is to operationalize and quantify (i.e., define and measure in numerals) human and social phenomena (e.g., language learning and teaching) in terms of "variables" and to verify hypotheses about the relationships (e.g., causal or correlational relationships) among different variables (for a theoretical alternative to physicalism and positivism in understanding human actions, see Taylor, 1985).

It is not a trivial point to note that the Enlightenment philosophers were typically males who theorized and philosophized in a historical period when they occupied privileged social and economic positions with slaves and surfs attending to their everyday practical needs, thus freeing them to do their theoretical work. Today we can see the shadows of parallel structures of gendered and racialized division of labor in academic disciplines and in TESOL, a discipline which models itself on its parent disciplines. In the TESOL field, those who teach future professors and researchers are at the top; those who teach future ESL/EFL teachers come next; and those who teach ESL or EFL are at the bottom, and it is typically females (and among them, many women of color) who fill up the ranks at the bottom. 
Feminist standpoint theorists have pointed out the unfortunate epistemological consequences of such gendered segregation of labor. They hold that movements for social liberation advance the growth of knowledge. As summarized by Harding:

[Feminist standpoint theorists] explicitly call for women of color, working-class women, and lesbians to be present among the women whose experiences generate inquiry. They all discuss the limitations of sciences emerging only from white, western, homophobic, academic feminism. (Harding, 1996, p. 311)

In our lived experiences, we note that it is precisely this gendered and racialized theory--practice divide in our discipline that has contributed to the inadequate generation of theories of practical knowledge that are relevant to the work of frontline TESOL practitioners. The experiences and activities of the majority of frontline TESOL workers (typically female classroom teachers, and many are people of color) do not have a chance to enter into the ranks of prestigious mainstream theories and research as frequently they are not given the institutional resources, time, and opportunities to theorize their experiences and share and publish them in the discipline's prestigious journals.

Apart from the negative epistemological consequences, there are also grave political consequences of this gendered and racialized theory--practice divide. As the knowledge generated by the experiences and activities of female researchers and teachers, of people of color, of different social classes and sexualities does not have a chance to enter into the discipline's knowledge base and cannot contribute to the content of the discipline's curriculums, students coming from these dominated groups consistently do not get the kinds of knowledge and theories that speak to and value their own lived experiences as minorities in society.

\section{E. Where I am now}

Where do I stand now? I felt that I am not just an 'Asian', a 'Chinese', a 'non-native English speaker of color' (though people in general will still identify and classify me with such labels). I felt that I had been able to develop an identity that's broader than just being Hongkongese or Chinese, or a person of color, but as a human being reaching out to other fellow human beings, forming friendships above and across cultural and ethnic lines; different, yet not an OTHER. English is very much part of me now. Yes, I speak English with an accent, but I promise myself that I'll resist it when occasions arise where some people might try to make me feel ashamed of my accent, to feel that I'm an OTHER. And I'll say to them: I am like you, but I'm not really you, or: No, I'm not you, but I am like you (Trinh T. Min-ha, 1990). Like what Trinh Min-ha says: there’s an OTHER within every I; and perhaps I can also say this too: there's an English OTHER within a Chinese I, or equally true, a Chinese OTHER within an English I.

Yet, today, I'm agonized, seeing that many students of English have such an unpleasant experience with English. Perhaps it's like how I felt when I was frustrated by the difficult English vocabulary in my textbook in Primary 3. Perhaps more importantly, they need to develop a new relationship with English, and find new identities for themselves that are 
more than just "Hong Kong Chinese who need English for exams". English, as I have known it for years, is not and should not be seen as the language of only those people living in or coming from "English-speaking countries". English should not be exclusively owned by the English-speaking British, Americans, Australians or Canadians. English in its many diverse ways, in its many rich accents, should be accessible and should belong to anyone who wants it. English should also allow itself to be enriched, expanded, and hybridized by people living in different parts of the world. And I see that non-native English teachers and TESOL professionals of color can have an important contribution to make to TESOL in shifting the ownership of and authority over English (as communicative resources) to more learners and teachers of diverse ethnic/linguistic backgrounds in the World. They should not always be relegated to duties and roles placed at the bottom of the ranks simply because of the market ideology that white faces sell (i.e., the ideology that putting white faces and names in leadership positions add symbolic prestige to the institute and the programmes).

How do I help my students to turn English from an enemy to a friend, to make use of this medium to express, expand and, possibly, enrich their lives, to transform or hybridize their current identities, to enter into a new world of possibilities as well as relationships with other cultures and peoples in the world? We cannot just ignore English-no matter how much we might wish we could; we have to come to terms with English, not as a neutral tool of communication, albeit how much we would like to happily believe that. Instead we have to be fully aware of its power and its gate-keeping functions, fully aware of how it gets its power over us, and yet re-appropriating it, hybridizing it, with our own accents, and ultimately to own it. I can never forget what a 14-year-old secondary school student told me: "English is so boring and so difficult; I can never master it; but the society wants you to learn English; without English, you can’t find a good job!” His words keep coming back to haunt me. It's a dilemma a response to which I'm still working on. Perhaps the cyber age in the new millennium presents new spaces, new media, and new possibilities for experimenting with new forms of English, new hybridized identities, and new hybridized communities; and perhaps we can work towards helping ourselves to develop and engage in new practices whereby learning and speaking another language is not a continuation of the processes of OTHERING, so much of which we have already witnessed in this world.

\section{F. Towards a Communicative Ethic of Togetherness-in-Difference: From TESOL to Teaching English for Dialogic Communication in a World of Diversity}

The TESOL discipline needs to be re-visioned and reshaped in our increasingly glocalized world of diversity. Instead of taking as our disciplinary goal the finding and gaining of certain (as opposed to situated, uncertain) knowledge of the most effective technology (as if there exists a universally effective technology) to teach English to speakers of other languages, a more urgent task seems to be that of finding situated, dialogic, glocalized ways of teaching and learning English for relatively constraint-free understanding and communication (Fricker, 2000) and achieving a sense of togetherness-in-difference (Ang, 2001) among people coming from very different locations (geographical and/or social) and with very different sociocultural experiences (see Wong, forthcoming; Lin \& Luk, 2005). The traditional technicalized concerns of the discipline need to be expanded by equally 
important concerns about how to value linguistic and cultural diversity and promote social justice in the (often hegemonic) spread of English in different parts of the world.

In embarking on this writing project, I am not aiming at "narrating [my] suffering”, nor am I "invested in rewards" (Velez, 2000, p. 325). What gives meaning to this job and profession of ours as we continue to work as women faculty of color in TESOL? As sociohistorically constructed as a 'woman', a 'person of color', and a 'non-native English speaker', we are triply disadvantaged by all the labels of marginalization and exclusion. In the hierarchy of the TESOL industry such pigeon-holing identities have the effect of placing women of color at the bottom ranks of the profession, and forming an implicit 'caste system' where persons of color are consistently excluded or marginalized with such marginalization made invisible and legitimate through all kinds of naturalized ideologies (e.g., the market ideology that white faces and names sell in an ESL or EFL programme).

With few faculty of color as role models to school children of diversity the invisible ideologies that privilege white faces and white names as legitimate speakers of English and authoritative figures/experts in TESOL will only continue to perpetuate, to the effect that children of color might also internalize the ideology that white persons are the 'best' ESL/EFL teachers. It is my hope that our work will contribute to a world where there is more intercultural understanding, and less marginalization and discrimination due to various ideological and institutional structures, and a world in which children and students of different racial/ethnic, linguistic, social, and gender backgrounds can have their identities and experiences valued and their potential affirmed and developed in their English language education. That, however, cannot happen without a serious problematizing of the kinds of marginalization and exclusion that the TESOL industry and profession perpetuate.

\section{References}

Ang, I. (2001). On not speaking Chinese: Living between Asia and the West. London: Routledge.

Bourdieu, P. (1982/1991). Language and symbolic power. Cambridge, Mass.: Cambridge University Press. [original published in French in 1982]

de Certeau, M. (1984). The practice of everyday life. Berkeley: University of California Press.

Delpit, L. D. (1988). The silenced dialogue: Power and pedagogy in education other people's children. Harvard Educational Review, 58(3), 280-298.

Harding, S. (1996). Feminism, science, and the anti-Englightenment critiques. In A. Gary, \& M. Pearsall (Eds.), Women, knowledge, and reality: Explorations in feminist philosophy (pp. 298-320). New York: Routledge.

Smith, D. (1974). Women's perspective as a radical critique of sociology. Sociological Inquiry, 44, pp. 7-13.

Smith, D. (1987). The everyday world as problematic: A feminist sociology. Boston: Northeastern. 
Fricker, M. (2000). Feminism in epistemology: Pluralism without postmodernism. In M. Fricker, \& J. Hornsby (Eds.), The Cambridge companion to feminism in philosophy (pp. 146-165). Cambridge: Cambridge University Press.

Gee, J. P. (1996). Social linguistics and literacies: Ideology in discourses (2nd ed.). London: Taylor \& Francis.

Goldstein, T. (2003). Teaching and learning in a multilingual school: Academic and linguistic dilemmas. Mahwah, New Jersey: Lawrence Erlbaum.

Lave, J., \& Wenger, E. (1991). Situated learning: Legitimate peripheral participation. Cambridge: Cambridge University Press.

Lin, A. (1996). Doing-English-lessons in secondary schools in Hong Kong: A sociocultural and discourse analytic study. Unpublished doctoral dissertation, University of Toronto, Canada.

Lin, A., Wang, W., Akamatsu, A., \& Riazi, M. (2002). Appropriating English, expanding identities, and re-visioning the field: From TESOL to teaching English for glocalized communication. Journal of Language, Identity and Education, 1 (4), pp. 295-316.

Lin, A., \& Luk, J. (2005). Local creativity in the face of global domination: Insights of Bakhtin for teaching English for dialogic communication. In J. K. Hall, G. Vitanova, \& L. Marchenkova. (Eds.), Dialogue with Bakhtin on second and foreign language learning: New Perspectives (pp. 77-98). Mahwah, New Jersey: Lawrence Erlbaum.

Lippi-Green, R. (1997). English with an accent: Language, ideology, and discrimination in the United States. London: Routledge.

Liu, J. (2000). Towards an understanding of the internal colonial model. In D. Brydon (Ed.), Postcolonialism: Critical concepts in literary and cultural studies, Volume IV (pp. 1347-1364). London Routledge.

Taylor, C. (1985). Human agency and language. Cambridge: Cambridge University Press.

Trinh, T. M-H. (1990). Not you/like you: Post-colonial women and the interlocking questions of identity and difference. In G. Anzaldua (Ed.) Making face, making soul. San Francisco: An Aunt Lute Foundation Book.

Velez, D. L. (2000). Anger, resentment, and the place of mind in academia. In The Social Justice Group at the Centre for Advanced Feminist Studies, University of Minnesota (Ed.), Is academic feminism dead? Theory in practice (pp. 311-326). New York: New York University Press.

Wong, S. (forthcoming). Dialogic approaches to teaching English to speakers of other languages: Where the gingko tree grows. Mahwah, New Jersey: Lawrence Erlbaum. 